\title{
LAZER DOMÉSTICO EM TEMPOS DE PANDEMIA DA COVID-19
}

Recebido em: 10/08/2020

Aprovado em: 05/09/2020

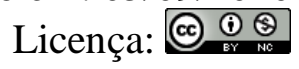

\author{
Ana Cristina Fernandes Clemente ${ }^{1}$ \\ Edmur Antonio Stoppa ${ }^{2}$ \\ Universidade de São Paulo (USP) \\ São Paulo - SP - Brasil
}

RESUMO: O presente artigo tem como objetivo apresentar as vivências de lazer mais presentes em tempos de pandemia da Covid-19 e suas relações com os conceitos e as barreiras socioculturais do lazer. Considerando as políticas de quarentena e isolamento social, as vivências de lazer se restringiram ao espaço do lar, surgindo assim novas possibilidades ligadas ao ambiente virtual e também ao ambiente doméstico, como lives musicais, crescimento do uso de plataformas de streaming para filmes, séries, música, jogos, assim como atividades físicas, gastronômicas, jardinagem e roteiros turísticos virtuais. Embora encontradas vivências adaptadas ao espaço do lar, houve também a intensificação de barreiras socioculturais relativas ao nível econômico, grau de instrução, acesso a espaços e equipamentos de lazer, acesso à internet, entre outras. A metodologia foi composta por pesquisa bibliográfica e documental em livros, artigos acadêmicos, publicações e conteúdo jornalísticos ligado a lazer, entretenimento, consumo e lazer doméstico, assim como de órgãos e instituições relacionados a lazer, cultura e turismo em conjunto com alguns levantamentos sobre o novo coronavírus. Como resultado está a existência de novas vivências de lazer e a transformação de algumas que até então eram desenvolvidas em ambientes externos à casa.

PALAVRAS-CHAVE: Atividades de Lazer. Lazer Doméstico. Covid 19.

\section{DOMESTIC LEISURE IN COVID 19 PANDEMIC TIMES}

ABSTRACT: This article aims to present the leisure experiences most present in pandemic times of Covid-19 and their relationship with the concepts and socio-cultural barriers of leisure. Considering the quarantine and social distancing policies, leisure experiences were restricted to the home space, thus emerging new possibilities related to the virtual environment and also the domestic environment, such as musical "lives", use of streaming platforms for films, series, music, games, as well as physical exercises, cooking and gardening activities and virtual tours. Although it was possible to find

\footnotetext{
${ }^{1}$ Doutoranda em Turismo pela EACH USP. Mestre em Turismo pela EACH USP. Atua na Secretaria de Turismo do Estado de São Paulo.

2 Doutor em Estudos do Lazer, Docente da Escola de Artes, Ciências e Humanidades (EACH), da Universidade de São Paulo (USP), nos cursos de Graduação em Lazer e Turismo e no Programa de PósGraduação em Turismo, nível Mestrado e Doutorado. É líder do Grupo Interdisciplinar em Estudos do Lazer (GIEL) e participante do ORICOLÉ (EEFFTO-UFMG).
} 
experiences adapted to the home space, there was also the intensification of socio-cultural barriers related to the economic development level, education level, access to leisure spaces and equipment, internet access, among others. The methodology consisted of bibliographic and documentary research in books, articles, publications, news and jornalistic content related to leisure, entertainment, consumption and domestic leisure, as well as organs and institutions related to leisure, culture and tourism in line with some surveys related to the new coronavirus. As a result, there is the existence of new leisure experiences and the transformation of some that until then were developed outside their houses.

KEYWORDS: Leisure Activities. Domestic Leisure. Covid 19.

\section{Introdução}

Na cidade Wuhan, capital da província de Hubei, na China, em dezembro de 2019, uma doença denominada como novo coronavírus (Covid-19), teve seu foco inicial, alastrando-se de forma gradual por todo o mundo. Apesar de apresentar um baixo nível de fatalidade quando comparada a outras doenças globais recentes, como a SARS e a Gripe A (H1N1), a Covid-19 apresenta um grau de disseminação e contágio muito superior. Em decorrência disto, o quadro pandêmico da doença ocasionou uma grave crise no setor da saúde pública global, trazendo consequências grandiosas aos setores econômico e social de todo o mundo.

Segundo o relatório do Centro de Sistemas Científicos e Engenharia do Johns Hopkins (CSSE), até o dia 09 de agosto de 2020 foram registrados 19.739 .897 casos de Covid-19 e um total de 726.693 óbitos no mundo. Os países com maior número de casos são os Estados Unidos (cerca de 5 milhões); o Brasil (aproximadamente 3 milhões) e a Índia (2.1 milhão de casos). Esses países ultrapassaram em grande escala a China, onde a epidemia iniciou em dezembro de 2019, com 88 mil casos registrados (JOHN HOPKINS UNIVERSITY, 2020).

No Brasil, segundo o Ministério da Saúde, foram registrados 3.035.422 casos da doença e 101.049 mortes até dia 09 de agosto de 2020. O maior número de casos está no 
estado de São Paulo, com 627.16 casos e 25.144 óbitos, sendo o estado com maior número de casos do país (BRASIL, 2020; SÃO PAULO, 2020b).

A fim de evitar uma calamidade ainda maior, diversas medidas políticas foram tomadas para ajudar a reduzir a dispersão da doença, como confinamento, quarentena, redução de atividades não essenciais, retomada gradual das atividades econômicas e adoção de protocolos sanitários. As consequências de tais medidas impactaram nas formas de convívio social, de trabalho e de vivências de lazer que se restringiram principalmente ao ambiente doméstico.

Assim, foram reinventadas e recriadas algumas atividades de lazer nos lares e restringidas viagens, festividades, shows, cinemas, teatros, uso de parques urbanos e naturais, prática de esportes ao ar livre ou em ambientes fechados, clubes, museus e centros culturais, associativismo, entre outras. Em contrapartida, houve um incremento em grande escala no uso de plataformas digitais, como YouTube, Netflix, Globoplay, redes sociais, canais de notícias, televisão, assim como advento de programas para realização de encontros online ou reuniões, como Zoom, Meets, entre outros.

O isolamento social transformou e adaptou muitas vivências de lazer, restringiu as escolhas das pessoas agora limitadas ao ambiente doméstico e tornou algumas barreiras socioculturais mais evidentes, principalmente ligadas a questões econômicas, ao grau de instrução, a restrição de acesso a espaços e equipamentos de lazer e ao reordenamento do tempo e do espaço de lazer e de trabalho (MARCELLINO, 2006). Podem ser identificadas também barreiras como a limitação de acesso à internet ou mesmo a carência de habilidades para seu uso otimizado, crítico e criativo.

Diante desse cenário, o objetivo desse artigo é apresentar as vivências de lazer mais presentes em tempos de pandemia da Covid-19 diante da política de isolamento 
social e suas relações com os conceitos e as barreiras socioculturais do lazer no Brasil, exemplificados principalmente em São Paulo, um dos pontos focais da doença.

A metodologia foi composta majoritariamente por pesquisa bibliográfica e documental (SEVERINO, 2007) em fontes de dados secundários listados abaixo, e por análise de conteúdo dos dados obtidos (TRIVIÑOS, 2013):

- Publicações de órgãos públicos e associações ligadas ao lazer, turismo e cultura;

- Apresentação de ações organizadas pela Secretaria de Turismo do Estado de São Paulo, Secretaria de Cultura e Economia Criativa do Estado de São Paulo, Prefeitura de São Paulo, entre outros;

- Conteúdo jornalístico ligado a consumo, lazer e entretenimento;

- Conteúdo jornalístico ligado às plataformas online de música, filmes, séries, jogos, arte, entre outros;

- Ações criadas pelas pessoas e por empresas dentro do lar.

Os estudos e dados apresentados se referem ao período da pesquisa, de 10 de julho a 10 de agosto. Considerando que a pandemia da Covid-19 ainda está presente em países como o Brasil, considera-se que novas ações, políticas e vivências de lazer podem surgir. Mas espera-se que os dados dessa pesquisa contribuam com um registro acadêmico do que o mundo tem passado e auxilie no desenvolvimento de políticas de lazer democráticas e participativas.

O artigo está estruturado inicialmente apresentando uma contextualização da pandemia em meio a uma sociedade carente de líderes em um ambiente carregado de incertezas e inseguranças. Na sequência são apresentados conceitos ligados ao ambiente doméstico, suas limitações e usos. Em continuidade é apresentada uma contextualização sobre o lazer na sociedade atual e as vivências de lazer mais presentes no período de pandemia do novo coronavírus, focadas principalmente ao ambiente virtual e doméstico, 
com opções de entretenimento. As discussões seguem tratando das barreiras socioculturais do lazer, finalizando com as considerações finais.

\section{Colocações sobre a Pandemia da Covid-19}

Para Boaventura de Sousa Santos a pandemia veio agravar uma crise que o mundo enfrenta há 40 anos, uma crise que ninguém se dispõe em resolver. As crises deveriam ser passageiras, mas viraram uma resposta fácil para os problemas presentes na sociedade. Crises financeiras, por exemplo, para explicar os cortes de políticas sociais e degradação dos salários (SANTOS, 2020), bem como as crises ambientais para justificar a falta de alimentos e a pobreza, as crises sociais ao visualizarmos a xenofobia, a violência contra mulheres e as represálias contra comunidades tradicionais, ou ainda as guerras para justificar o terrorismo e a falta de cooperação entre os países.

De acordo com Harari (2020), houve um esforço grande em prol da globalização, mas atualmente tem se falado de "desglobalizar" o mundo, construindo muros, restringindo viagens, reduzindo o comércio. Entretanto, segundo o autor a saída não é a segregação, mas sim a cooperação, com o compartilhamento de informação, promoção e intensificação de ações de solidariedade e fortalecimento da confiança e da cooperação internacional. De acordo com Harari, estamos passando por um período em que o mundo está sem líderes, pois

[...] hoje, a humanidade enfrenta uma crise aguda não apenas por causa do coronovírus, mas também pela falta de confiança entre os seres humanos. Para derrotar uma epidemia, as pessoas precisam confiar nos especialistas, os cidadãos precisam confiar nos poderes públicos e os países precisam confiar uns nos outros. Nos últimos anos, políticos irresponsáveis solaparam deliberadamente a confiança na ciência, nas instituições e na cooperação internacional (HARARI, 2020, p. 8.).

Um artigo e webinar de Oscar Motomura, CEO da Amana Key, uma das principais consultorias de gestão do país, destaca em relação aos governantes eleitos que 
contexto de pandemia global. Nesse aspecto, estão todos zerados. Haverá os que estão pensando: "não fui eleito para isso..." (MOTOMURA, 2020, p.2).

Na prática muitos líderes estão tomando decisões precipitadas ou pensadas a partir de interesses próprios, sem relação com o interesse público. Há também divergência de opiniões entre esfera de governos locais e nacionais, desacordos com orientações de organizações globais, gerando mais medo e insegurança a população que não sabe quem ouvir ou seguir, ou mesmo não sabe quem cobrar. Nesse sentido, é necessário desenvolver políticas públicas e ações sociais pensadas para garantir o bem estar dos sujeitos, de forma democrática e eficiente, a partir de decisões que avaliem seus impactos e benefícios econômicos e sociais.

Em outra direção, positivamente Fois-Braga e Brusadin (2020) apontam que a pandemia pode ser uma forma de se repensar as vidas e formas de pensar dos sujeitos, permitindo olhar para nós mesmos. As pessoas estão afastadas de muitos ambientes que eram palco de suas rotinas. As regras e restrições vivenciadas podem gerar a reflexão e a crítica da sociedade vigente, na busca de melhores condições de vida.

Nesse cenário, as questões vinculadas ao lazer podem também ser tempo e espaço de novas reflexões. Neste artigo o lazer é entendido como uma cultura vivenciada, fruto da sociedade urbana, desenvolvido como uma das áreas de manifestação humana em estreita relação com outras esferas de atuação, como o trabalho, a educação, entre outras áreas, podendo exercer valores questionadores na sociedade (MARCELLINO, 2006).

Assim, é um tempo privilegiado para a vivência de valores que contribuam para transformações na sociedade atual, possibilitando, como reivindicação social, o resgate da cidadania por meio da participação cultural, entendida por Marcellino (2006, p.17), como "[...] a atividade crítica e criativa de sujeitos historicamente situados", podendo ser considerada como uma das bases para a mudança da sociedade, mudança em busca da instauração de uma nova ordem social e cultural.

licere, Belo Horizonte, v.23, n.3, set/2020. 
A participação, em sentido amplo, está associada à atitude que o indivíduo assume e não necessariamente à prática ou ao consumo em uma vivência de lazer. Os níveis de participação vão de conformismo, no qual o indivíduo concorda com as imposições da sociedade sem, no entanto, buscar e propor mudanças, até os níveis crítico e criativo, que buscam mudanças e melhorias nas condições atuais e na qualidade de vida dos sujeitos (MARCELLINO, 2006).

As formas de participação durante a pandemia foram intensificadas, principalmente, no ambiente virtual, com uso exaustivo de redes sociais, mas também com carreatas, "buzinaços" e "panelaços" na janela dos prédios e casas, legitimando causas ligadas ao sistema de saúde, feminismo, educação, racismo (black lives matter), assim como ligadas a democracia, ao consumo local (compre do local), a insatisfação com líderes governamentais, com os diferentes discursos políticos presentes no país, radicais posturas relacionadas a gestão da crise do novo coronavírus, divergências entre executivos municipais, estaduais e federais, entre outros assuntos.

\section{Vivências de Lazer no Ambiente Doméstico}

Diante das questões apontadas acima, os lares, classificados como espaços não específicos de lazer, bem como, as ruas, os bares e escolas, pois não foram criados para tal função, mas que podem cumprir esse papel (MARCELLINO, 2006) com a pandemia do Covid-19 se tornou praticamente a única possibilidade de vivência do lazer, apesar de muitas pessoas não cumprirem com à política de isolamento social implantada em muitos países no mundo, incluindo o Brasil, que visa reduzir a disseminação da doença.

A fase de isolamento social durou de forma mais rígida de março a junho de 2020 na maioria dos estados do Brasil. Atualmente (final de julho e início de agosto), muitos países estão em fase de retomada das atividades econômicas e sociais e os equipamentos 
de lazer estão sendo reabertos de forma gradual por vários estados do país, talvez ainda em uma fase de alto contágio.

No entanto, sem a vacina muitas pessoas ainda trabalham e disfrutam do tempo disponível em suas casas, devido ao medo e incerteza com a pandemia. Protocolos sanitários têm sido implantados como uso de máscara facial, álcool em gel, medição de temperatura para entrar em ambientes fechados, distanciamento entre as pessoas, adequação de horário de funcionamento de espaços de lazer e dos estabelecimentos de alimentação.

Com isso, observamos inúmeras transformações no campo do lazer e do turismo durante esse período de pandemia da Covid-19, como roteiros turísticos virtuais, aulas, shows e apresentações culturais no formato de "lives" - transmissões ao vivo em plataformas de streaming ${ }^{3}$. Além disso, essa crise sanitária forçou o maior convívio social para aqueles que moram com suas famílias ou o completo isolamento para os que moram sozinhos.

Uma questão muito importante em relação à casa como espaço de lazer é que muitos lares não foram preparados para presença diária e conjunta de todos os seus membros. Antes, com as longas jornadas de trabalho e deslocamentos até o ambiente profissional, principalmente para os que vivem em grandes cidades, as pessoas criaram o hábito de se manter muito tempo fora dos lares, exceto nos finais de semana, feriados e período de férias. A pandemia forçou todos a ficarem em seus lares como único meio de proteção contra o vírus que se espalha rapidamente.

Segundo Marcellino (2006) somente uma parcela privilegiada da população possui condições satisfatória de vivenciar o lazer em seus lares. A grande maioria vive em espaços pequenos de apartamentos, conjuntos habitacionais, favelas e construções não

\footnotetext{
${ }^{3}$ Conteúdo disponível em grande escala sem a necessidade de download.
} 
planejadas com reduzidas opções para convivência, lazer, trabalho e estudos. Com a pandemia inclusive as áreas coletivas de condomínios mantiveram-se fechadas e foram adotadas campanhas de redução da circulação nos prédios e em suas instalações comuns.

De acordo com artigo de Aresta e Salingaros (2020, p.1), no site de arquitetura ArchDaily, em relação aos lares

[...] é evidente que a arquitetura doméstica não está preparada para articular-se a um ser humano ou a uma família com múltiplas atividades e em constante mudança e trânsito de ações, sentimentos e pensamentos. Embora este seja um problema da arquitetura em geral, nesses tempos, as deficiências da arquitetura doméstica em responder tais necessidades humanas foram expostas.

Diante dessas colocações, as pessoas tiverem que reinventar suas rotinas de lazer, trabalho, tarefas domésticas e obrigações familiares agora unificadas no espaço do lar. A vivência do lazer, diante da pandemia da Covid-19, enfrenta desafios para o alcance dos mais altos níveis de participação, crítica e criativa, devido a sua limitação em escolhas e no uso de espaços e equipamentos.

Tratando-se das vivências de lazer mais comuns identificadas no período da pandemia da Covid-19, uma matéria da página do Jornal Valor Econômico mostrou um crescimento do consumo por televisores e de plataformas de transmissão de filmes e séries:

[...] para o entretenimento, a compra de TVs de tela fina no comércio eletrônico foram $71,1 \%$ maiores, acompanhando a procura pelos serviços de streaming de filmes e séries, que foi $27 \%$ maior. O aparelho de música micro system também teve aumento de $119,6 \%$ nas vendas nas lojas virtuais e os de jogos eletrônicos foram 5,4\% maiores no varejo total (MELO, 2020, p. 1).

Houve também um crescimento da audiência dos canais de televisão, cinco vezes maior que os últimos 5 anos, o que superou o total de usuários até em comparação a um período de Olimpíadas e Copa do Mundo ${ }^{4}$.

\footnotetext{
${ }^{4}$ Disponível em BOUÇAS, C. Audiência de TV é a maior em cinco anos. Valor Econômico. 2020. Disponível em: http://valor.globo.com/empresas/noticia/2020/04/03/audiencia-de-tv-e-a-maior-em-cincoanos.ghtml.
}

licere, Belo Horizonte, v.23, n.3, set/2020. 
Essas atividades de lazer citadas acima já tinham presença no mercado e aumentaram com a pandemia que forçou todos a ficarem em suas casas. Mas foram criadas vivências que antes eram realizadas presencialmente e tiveram que ser transferidas ao ambiente virtual, com é o caso das 'lives' de shows, concertos, tours virtuais, aulas de gastronomia, aula de ginástica, e muitas outras opções de lazer, sem contar reinvenção nas formas de trabalho e de estudos.

Uma pesquisa da Decode (2020), empresa de análise de dados do Banco de Investimentos BTG Pactual ${ }^{5}$, fez um estudo a partir de três fontes de dados: 1) das buscas realizadas no buscador Google (Google Trends); 2) dos downloads de aplicativos; e 3) dos dados de navegação em websites sobre as alterações de consumo da população brasileira elencando um conjunto de resultados ligados ao lazer e entretenimento. Abaixo estão alguns dos resultados dessa pesquisa reunidos com matérias jornalísticas sobre o uso de plataformas digitais e de algumas vivências de lazer e entretenimento em tempos de pandemia:

\section{Tabela 1: Vivências de Lazer e Entretenimento.}

\begin{tabular}{ll}
\hline Youtube & Mais de $40 \%$ da população brasileira acessou o Youtube em março de 2020, foram mais \\
& de 90 milhões de acessos únicos. Em complemento, uma pesquisa apresentada na \\
& Revista Exame mostrou que a busca por conteúdo online no YouTube aumentou \\
& $4.900 \%{ }^{6}$. \\
\hline Aplicativos & Foram mais de 6 milhões de downloads de aplicativos de música streaming como Spotify \\
de Música & e Deezer. Uma matéria do Estadão apontou que o Spotify chegou em 130 milhões de \\
& usuários, um aumento de $30 \%$, que foi além do esperado pela empresa7. \\
Lives & As buscas por “live streaming”, que basicamente são apresentações, shows e \\
& performances transmitidas por grandes plataformas online sem a necessidade de \\
& download do conteúdo, como Youtube, Instagram, Facebook, etc., aumentaram $85 \%$ \\
& entre fevereiro e abril de 2020 no Brasil. Em um total de 30 lives musicais brasileiras \\
& foram registradas 206 milhões de visualizações. Muitos cantores, cantoras e duplas do \\
& sertanejo e do pagode a fim de arrecadar fundos para pessoas com a doença ou pessoas
\end{tabular}

\footnotetext{
5 Disponível em DECODE, BTG Pactual. O Legado da Quarentena para o Consumo. Mai. 2020. Disponível em http://lp.decode.buzz/legado-da-quarentena-consumo.

${ }^{6}$ Disponível em AGRELA, L.; CURY, M. E.; VITORIO, T. Na quarentena, o mundo virou uma live. Revista Exame. 2020. Disponível em: http://exame.com/revista-exame/o-mundo-e-uma-live/.

${ }^{7}$ Disponível em O ESTADO DE SÃO PAULO. Spotify tem aumento de assinantes além do esperado durante a pandemia. Caderno Link. 2020. Disponível em: http://link.estadao.com.br/noticias/empresas,spotify-tem-aumento-de-assinantes-alem-do-esperadodurante-a-pandemia,70003287092.
}

licere, Belo Horizonte, v.23, n.3, set/2020. 
Lazer Doméstico em Tempos de Pandemia da Covid-19

Ana Cristina Fernandes Clemente e Edmur Antonio Stoppa

em vulnerabilidade começaram a fazer lives em suas casas. A dupla Jorge e Mateus e a cantora Marília Mendonça, um dos pioneiros na ação, conseguiram 3,1 e 3,3 milhões de visualizações, respectivamente. Foi recorde mundial segundo relatório da empresa Avellar (2020). Com isso, muitos artistas começaram a fazer performances ao vivo, como Bruno e Marrone, Sandy e Junior, Thiaguinho, Péricles, Henrique e Juliano e Raça Negra. No início da pandemia foi uma importante atividade de lazer. A audiência não era demonstrada somente pelo total de visualização dos vídeos, mas os shows viraram "top trends" do Twitter no país 8 .

Netflix A Netflix, plataforma mundial de filmes e séries, apresentou aumento de $29 \%$ no volume de downloads do aplicativo entre fevereiro e março. Foram cerca de 7,7 milhões de downloads no país. Com isso, buscas por home theater e tela de projeção também cresceram. Somente o Netflix teve um aumento de mais de 16 milhões de assinantes no mundo, somando mais de 180 milhões, de acordo com matéria da revista Exame ${ }^{9}$. Outra plataforma de streaming com aumento de assinantes foi o Globoplay com 2,5 vezes mais assinantes durante a pandemia ${ }^{10}$.

Gaming Houve aumento em $60 \%$ pelo interesse por consoles de vídeo game. O site de game stream Twich TV recebeu mais de 30 milhões de visitas, $25 \%$ a mais em fevereiro e março de 2020.

Jogos e Houve considerável crescimento pela procura de jogos físicos, não somente virtuais, brinquedos como mini-mesa de sinuca (cresceu 300\%), jogos de tabuleiro (aumento de 100\%), quebra-cabeça (98\% a mais) e mesa de ping-pong cresceu em $70 \%$, conforme buscas no Google Trends Brasil. Os jogos e brinquedos também demonstraram crescimento, em mais de $434 \%$, conforme aponta site mercado e consumo ${ }^{11}$.

Atividades Houve crescimento em $271 \%$ de download de aplicativos de atividades físicas, como Físicas $\quad$ BTFIT, NTC (Nike Training) e Adidas Training. A busca por acessórios para essas atividades em casa também cresceram, como de halter (pesos), colchonetes e elásticos para treino.

Cozinhar Cresceu o número de pessoas buscando informações sobre cozinhar em casa ou sobre aplicativos de delivery ligados a consumo de alimentos. Uma das procuras foi por receitas "gourmets", assim como de eletrodomésticos e acessórios de cozinha. A busca por receitas "gourmets" indica interesse por cozinhar enquanto vivência de lazer, um hobby por exemplo, não somente para sobrevivência. Além disso, somente em março foram registrados cerca de nove milhões de downloads de aplicativos de entrega, como Ifood, Uber Eats e Rappi.

Consumo de $\mathrm{O}$ consumo de vinho a partir do monitoramento de acesso a sites de venda de vinhos vinho também apresentou crescimento, com mais de 2 milhões de acessos em sites como wine.com, evino.com, grandcru.com, entre outros. Uma matéria do estadão mostrou que o consumo de vinhos subiu $72 \%$ no $2^{\circ}$ trimestre da quarentena, atingindo marca histórica $^{12}$.

\footnotetext{
${ }^{8}$ Tópicos mais citados no Twitter no Brasil.

${ }^{9}$ Disponível GODOY, D. Netflix ganha 16 milhões de assinantes. no primeiro trimestre com covid-19. Revista Exame. 2020. Disponível em: http://exame.com/negocios/netflix-ganha-16-milhoes-deassinantes-no-primeiro-trimestre-com-covid-19/.

${ }^{10}$ Disponível em RIBEIRO, F. Globoplay tem 2,5 vezes mais assinantes durante a pandemia do que em 2019. Canal Tech. 2020. Disponível em: http://canaltech.com.br/entretenimento/globoplay-tem-25-vezesmais-assinantes-durante-a-pandemia-do-que-em-2019-166725/.

${ }^{11}$ Disponível em MERCADO E CONSUMO. Brinquedos e jogos registram alta no e-commerce durante a pandemia. 2020. Disponível em: http://www.mercadoeconsumo.com.br/2020/05/06/brinquedos-e-jogosregistram-alta-no-e-commerce-durante-a-pandemia/.

${ }^{12}$ Disponível em SCHELLER, F. Consumo de vinhos sobe $72 \%$ no $2^{\circ}$. Trimestre e atinge máxima histórica na quarentena. O Estado de São Paulo. Caderno Economia \& Negócios. 2020. Disponível em:
}

licere, Belo Horizonte, v.23, n.3, set/2020. 
Jardinagem A busca por kit de jardinagem, de acordo com ferramenta de busca Google, cresceu em $180 \%$ de 17 de março a 17 de junho ${ }^{13}$, com opções de venda online. Cresceram também o número de páginas na internet com dicas de como plantar, fazer horta em casa, entre outros itens.

Fonte: Elaboração dos autores, com base nos dados da Decode (2020) e conteúdo jornalístico.

Complementando as informações apresentadas acima, algumas ações dos órgãos públicos e de iniciativas das pessoas ficaram famosas como importantes vivências de lazer:

- Cultura em Casa: a Secretaria de Cultura e Economia Criativa do Estado de São Paulo criou esse projeto que reúne um conjunto de conteúdos de museus, música, arte, dança, literatura para o público geral. Segundo o site, foram 850 mil visualizações em menos de dois meses e mais de 600 conteúdos culturais disponibilizados. Conta com informações como do Museu da Imigração, localizado na cidade de São Paulo, com fotos, textos da história e descritivo do local. No Museu do Café, em Santos, é possível encontrar exposições virtuais do acervo.

- Tours Virtuais: a Secretaria de Turismo do Estado de São Paulo tem promovido em parceria com as prefeituras municipais um conjunto de lives por atrativos turísticos, contando com guiamento e apresentação dos locais, como Edifício Martinelli, Beco do Batman, Catedral da Sé etc.

- Mutirão Turismo: a Secretaria de Turismo do Estado de São Paulo desenvolveu um site que reúne boas práticas ligadas ao turismo e cultura no estado de São Paulo. Há sites de compras de produtos locais, como de fazendas e propriedades rurais tradicionalmente famosas pela visitação turística, que estão com serviços

\footnotetext{
http://economia.estadao.com.br/blogs/fernando-scheller/consumo-de-vinhos-sobe-72-no-2o-trimestre-eatinge-maxima-historica-na-quarentena/.

${ }^{13}$ Disponível em RIBEIRO, C. Pandemia de Covid-19 aumenta interesse dos brasileiros em jardinagem e horta urbana. Revista Globo Rural. 2020. Disponível em: http://revistagloborural.globo.com/Colunas/Cassiano-Ribeiro/noticia/2020/06/pandemia-de-covid-19aumenta-interesse-dos-brasileiros-em-jardinagem-e-horta-urbana.html.
}

licere, Belo Horizonte, v.23, n.3, set/2020. 
de entrega. Foram identificadas ações também de confecção de máscaras, doações etc. ${ }^{14}$.

- Drive-ins com filmes e apresentações musicais: em São Paulo, o Memorial da América Latina e o Centro de Tradições Nordestinas foram os primeiros a estrear essa modalidade com sessão de cinema. Na sequência estádios como Allianz e espaços de eventos abriram para sediar shows e performances musicais no formato drive in, e assim, dentro de carros, respeitando distanciamento e os protocolos do Plano São Paulo ${ }^{15}$.

- Museus ao redor do mundo sem sair de casa: um conjunto de sites lançou a divulgação de visita em museus do mundo sem sair de casa, dentre eles o Museu do Louvre, na França, o Reino de Sofia, em Madri, o British Museum na Inglaterra, entre outros. Dentre os sites encontram-se Guia da Semana ${ }^{16}$, os Melhores Destinos ${ }^{17}$, o Catraca Livre ${ }^{18}$, entre outros.

- Música na janela: na Itália uma ação que ficou famosa ao redor do mundo foram cantorias e apresentações de música na janela de prédios e apartamentos residenciais. Variavam desde hino nacional, voz e violão, shows de rock, entre outros feitos para driblar o tédio da quarentena ${ }^{19}$.

\footnotetext{
${ }^{14}$ Disponível em SÃO PAULO, Governo do Estado, Secretaria de Turismo. Mutirão do Turismo. 2020c. Disponível em: http://mutiraodoturismo.com.br/.

${ }^{15}$ O Plano São Paulo é o documento que define as medidas de retomada das atividades econômicas do estado de São Paulo de modo gradual e faseada. Disponível em SÃO PAULO, Governo do Estado. Plano São Paulo. 2020d. Disponível em: http://www.saopaulo.sp.gov.br/planosp/.

${ }^{16}$ Disponível em CAPITANI, L. 15 museus ao redor do mundo sem sair de casa. Guia da Semana. 2020. Disponível em: http://www.guiadasemana.com.br/turismo/galeria/museus-para-conheceronline\#: : :text=Museu\%20do\%20Vaticano\%2C\%20Tate\%2C\%20Louvre,e\%20Metropolitan\%20est $\% \mathrm{C} 3$

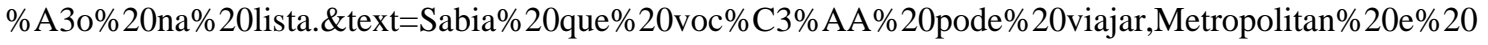
at $\%$ C3\%A9\%20o\%20MASP!.

${ }^{17}$ Disponível em RENNE, M. 30 museus virtuais para você visitar sem sair de casa. Melhores

Destinos. 2020. Disponível em: http://www.melhoresdestinos.com.br/museus-virtuais.html.

${ }^{18}$ Disponível em CATRACA LIVRE. Faça um tour virtual pelos museus mais icônicos dos EUA. Catraca Virtual. 2020. Disponível em: http://catracalivre.com.br/viagem-livre/faca-um-tour-virtual-pelos-museusmais-iconicos-dos-eua/.

${ }^{19}$ Disponível em G1. De quarentena por novo coronavírus moradores de cidades da Itália cantam nas janelas. Globo.com. Mundo. 2020. Disponível em: http://g1.globo.com/mundo/noticia/2020/03/13/dequarentena-por-novo-coronavirus-moradores-de-cidades-da-italia-cantam-nas-janelas-veja-video.ghtml.
}

licere, Belo Horizonte, v.23, n.3, set/2020. 
Dessa maneira, foram promovidos e organizados um conjunto de vivências de lazer que contemplam os conteúdos culturais do lazer ligados a sociabilidade, físicoesportivo, ao interesse intelectual, artesanal e turístico. Positivamente contribuiu para minimizar a ausência de espaços e equipamentos de lazer e promover o divertimento, descanso e desenvolvimento pelo lazer. Entretanto essas políticas adotadas para minimizar a pandemia geraram impactos consideráveis nos setores de cultura, lazer, entretenimento e turismo.

Em termos econômicos, as buscas por agências de viagem caíram cerca de $50 \%$ e por passagens aéreas houve queda de 35\% (DECODE, 2020). Em contraposição aos dados apresentados pela Decode, ligado a busca por viagens, em março os cancelamentos e adiamento de viagens foram uma das principais reclamações junto ao Procon-SP. Segundo Secretaria de Turismo do Estado de São Paulo, até 17 de março de 2020 foram registradas 1.903 atendimentos relacionados a cancelamentos de viagens e eventos, denúncias de preços abusivos e ausência de produtos. De acordo com o Procon-SP, 678 (51\% do total) das reclamações registradas foram contra agências de viagens e 546 (41\%) contra companhias aéreas (SÃO PAULO, 2020a) ${ }^{20}$.

Ainda em termos de impactos gerados, além do turismo, o setor de esportes foi nitidamente afetado, com cancelamento de campeonatos, jogos e partidas nas mais diversas modalidades. No futebol foram cancelados ou adiados jogos pelas federações do país, jogos da Champions League, na Europa, além de adiadas as eliminatórias da Copa do Mundo 2022, que será no Qatar. Na Fórmula 1 estavam programados 22 Grandes Prêmios (GPs) em 2020, incluindo o do Brasil que aconteceria na cidade de São Paulo e foi cancelado juntamente com as provas nos Estados Unidos e México. Depois de

\footnotetext{
${ }^{20}$ Disponível em SÃO PAULO, Governo do Estado - Secretaria de Turismo. Boletim de impactos do COVID-19 no Turismo., 2020a. https://www.turismo.sp.gov.br/publico/include/download.php?file=433. Acesso em: 09 ago. 2020.
}

licere, Belo Horizonte, v.23, n.3, set/2020. 
reformulado, o campeonato contará com somente 8 provas programadas para serem realizadas no continente europeu. Outra competição mundial de grande destaque, as Olimpíadas, que seriam realizadas em Tóquio, no Japão, em julho de 2020 foram adiadas para o mesmo período de 2021.

Em relação aos grandes eventos, os réveillons e carnavais de 2021 no Brasil foram cancelados ou não tem definição se serão realizados. Além deles, destaca-se também o cancelamento da Oktoberfest de Blumenau e as turnês musicais de artistas internacionais, como Backstreet Boys, Taylor Swift e The Offspring. Em São Paulo foram cancelados também eventos tradicionais, como Salão do Automóvel, a Parada do Orgulho LGBT, a Marcha para Jesus, o festival de rock Lollapalooza, o festival de flores de Holambra Expoflora, a Festa das Flores e Morangos de Atibaia, os rodeios e festas juninas, entre muitas outras.

O setor cultural e de economia criativa sofreu grande impacto, devido principalmente ao cancelamento e adiamento de eventos e de espetáculos. Algumas atividades migraram para o ambiente virtual, como consumo de bens e tecnologia, enquanto outras foram canceladas, conforme gráfico abaixo:

\section{Gráfico 1: Tendências de variação das atividades do setor de Economia Criativa.}

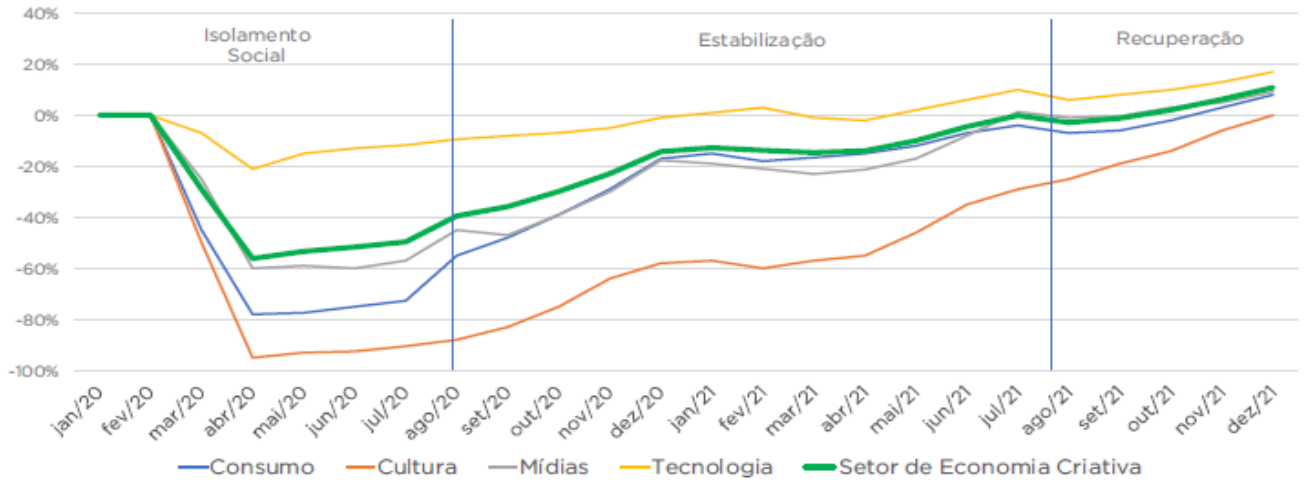

Fonte: FGV, 2020.

Essas vivências são realizadas no chamado tempo "livre”, ou mesmo “disponível”, mas diante desse cenário, usar esses termos gera certo questionamento, pois não foi uma 
atitude de livre escolha ficar em casa. Foi uma emergência sanitária que colocou grande parcela da população em suas casas para trabalhar, estudar, descansar, divertir-se e desenvolver-se individual e coletivamente.

Entendemos o lazer a partir dos apontamentos de Marcellino (2006), que afirma que o lazer deve ser conceituado a partir dos aspectos tempo e atitude, porém diante do momento que se vive a liberdade de uso do tempo e espaço de forma restrita, com leis e decretos limitando a circulação das pessoas, de modo a garantir a redução da disseminação do vírus, ressalta-se a necessidade de que o tempo e espaço da casa precise ser utilizado da melhor forma possível, a fim de que as vivências de lazer possam ser realizadas com mais possibilidades tanto de conteúdos, quanto dos níveis de participação para as pessoas.

Não somente a restrição de uso de espaços e equipamentos de lazer se traduz em uma barreira sociocultural identificada no lazer em tempos de Covid-19, que é refletida primeiramente no fechamento dos parques, museus, clubes, teatros, cinemas, praias, e demais locais, que estão gradualmente retornando seus funcionamentos com devidos protocolos sanitários, mas também as limitadas estruturas dos lares para vivência de lazer para a maioria das pessoas se traduz em uma barreira, como já colocado anteriormente.

Outra barreira que surge mais fortemente em meio a pandemia é o acesso à internet, pois muitas pessoas têm zero ou mínimo acesso a ela ou não possuem aparelhos adequados para otimização do seu uso. Segundo Pesquisa Nacional por Amostra de Domicílios (PNAD) de 2018 do IGBE (Instituto Brasileiro de Geografia e Estatística) cerca de 46 milhões de brasileiros não tem acesso a rede de internet, o que representa 1 em cada 4 brasileiros (IGBE, 2018).

Tratando-se da barreira econômica em suas relações com a barreira de acesso a internet é possível considerar que a maioria das vivências de lazer listadas acima, ligadas 
ao uso de plataformas digitais, consumo e entretenimento, são claramente voltadas às classes sociais com maior poder econômico e, com isso, com condições de custear tais experiências, que não são proporcionadas no mesmo nível de acesso para as pessoas de classes sociais com nível econômico menor.

Segundo pesquisa PNAD COVID-19, do IBGE, até julho de 2020 cerca de 3 milhões de pessoas perderam o emprego devido a pandemia do novo coronavírus, somando mais de 12,9 milhões de pessoas desocupadas no país (IBGE, 2020a). Além disso, são mais de 18 milhões de pessoas que não procuraram emprego por conta da pandemia ou por falta de trabalho na localidade e mais de 24 milhões tiveram rendimento menor do que o normalmente recebido (IBGE, 2020b). E ainda, 44\% dos domicílios da amostra recebem auxilio emergencial do Governo Federal. De acordo com matéria da UOL, a Caixa Econômica Federal já pagou 66,9 milhões de brasileiros com o beneficio do auxilio emergencial implantado para minimizar os impactos econômicos no país devido a pandemia (DECLOEDT, 2020).

De acordo com o FMI (Fundo Monetário Internacional) a considerar por pandemias anteriores, a Covid-19 irá exacerbar as desigualdades sociais, tornando as pessoas pobres cada vez mais pobres. Segundo instituição, aqueles com empregos de nível de escolaridade superior quase não serão afetados e os com escolaridade baixa serão drasticamente afetados (FURCERI, LOUNGANI, OSTRY, 2020).

Dessa forma, as vivências de lazer das classes sociais com menores condições econômicas ficam comprometidas, com poucas opções e oportunidades devido aos custos da maioria das vivências de lazer doméstico, além do fato de que muitas pessoas dessas classes sociais continuam trabalhando, quer seja em serviços essenciais para a sociedade, quer seja devido ao fato de precisarem de recursos financeiros para subsidiar sua vida pessoal e de seus familiares e assim, continuaram suas rotinas de trabalho ou perderam o 
emprego, sem condições de vivenciar o lazer de forma que permita o alcance de maiores graus de satisfação e de participação.

Outra barreira que impacta no alcance dos níveis mais altos de participação é o grau de instrução, que dessa vez não está somente ligado a educação básica, mas também as competências e habilidades para uso das novas tecnologias e imersão no ambiente virtual que cresce exponencialmente em relação a aplicativos, sites, redes sociais e canais de informação, no qual nem todos tem entendimento de uso.

Outra barreira é a própria capacidade de análise crítica do conteúdo que é impulsionado nas plataformas digitais. Tem-se presente nesse universo o lazer mercadoria, que segundo Marcellino (2008, p. 24)

[...] não [são] as atividades populares ligadas a alma da população, mas "popularescas", no sentido de nivelamento "por baixo", com único objetivo de "desviar a atenção de", e esse "de", quase sempre, pode ser entendido como a triste realidade pessoal e social dos seres humanos. É a distração, significando alheamento e não, como propõe o educador Rubem Alves, como 'atração por um outro mundo'. Um mundo diferente, de sonho e invenção, de uma sociedade mais justa, de um ser, mais humano.

Grande beneficiada e produtora desse entretenimento é a Indústria Cultural, caracterizada principalmente pelas mídias de massa, como a televisão e internet, que contribuem com essa percepção de lazer mercadoria, manipulando as ideias e opiniões públicas, produzindo uma cultura de massa, aquela que "nivela por baixo", ou seja, traz conteúdos de baixo conhecimento e profundidade para tentar atingir a compreensão de todos (MARCELLINO, 2008).

O entendimento do lazer pela sociedade, nos dias atuais, está muitas vezes relacionado a uma perspectiva funcionalista, que o entende, fundamentalmente, enquanto válvula de escape, vivenciado de modo a ajudar as pessoas a conviverem com as injustiças sociais observadas no cotidiano, colaborando com a manutenção da situação social vigente e também com a elaboração de políticas públicas de lazer reduzidas, sem relação 
com as realidades locais, pouco democráticas ou mesmo eficientes (MARCELLINO, 2008).

É necessário pensar em políticas e iniciativas que estimulem os níveis mais altos de participação, crítico e criativo. Dessa forma os conteúdos absorvidos devem passar por uma peneira crítica, que permitam estimular a participação dos sujeitos na sociedade, permitindo sua mudança, para uma sociedade mais inclusiva, justa, responsável e harmoniosa.

Outros elementos que tem impactado a sociedade atual antes mesmo na pandemia são o estresse, a depressão e de doenças mentais que afetam também as formas de apropriação e de alcance dos mais altos níveis de participação nas vivências de lazer. As políticas de lazer e principalmente as políticas de saúde devem levar isso em consideração, não a partir de uma perspectiva funcionalista, mas de modo amplo, considerando que tais questões impactam na sociedade e hoje, mais do que nunca, com o isolamento social, o medo de contágio e as tragédias divulgadas constantemente pela mídia afetam as pessoas, suas famílias e modos de vida, de trabalho e de usufruir o lazer. Somado a isso se encontram também problemas de violência doméstica, negligência com as crianças e adolescentes, entre outros. Assim, os questionamentos sociais devem partir de uma visão otimista pensados na mudança e não na alienação e no conformismo.

Avançando nas discussões, além de barreiras encontradas para uso de espaços e equipamentos de lazer específicos e não específicos, ou mesmo de barreiras econômicas e de instrução educacional, além das associadas ao acesso à internet e a saúde, há também o reordenamento do tempo. Muitas pessoas começaram a trabalhar de suas casas e se mantém conectados praticamente o dia todo com seus superiores e empresas, perdendo noção de tempo, visto que o espaço de lazer e trabalho são os mesmos como nas sociedades rurais de antigamente. 
Em termos de trabalho se disseminou o regime de home office, ou de teletrabalho, que na verdade implica em dizer que se tem um "escritório em casa", o que não traduz a realidade atual, com adequações e restruturação de espaços que estavam sendo utilizado para outros fins como uma forma de sobrevivência a cobranças dos empregadores.

Um monitoramento da empresa Hibou no mês de 2020 revelou que seis em cada dez brasileiros no início da pandemia estavam trabalhando em regime de home office. Desse montante, $25 \%$ acredita estar trabalhando mais do que o comum, dentre as razões colocadas estava o medo de ser despedido (LORRAN, 2020).

Outro fator que intensificou as jornadas de trabalho foi a necessidade de definir medidas emergenciais para mitigar os impactos da pandemia nos negócios e nos governos, forçando as pessoas a trabalharem mais para pensarem soluções rápidas. No momento, com a reabertura dos escritórios e a retomada de algumas atividades, esse número provavelmente reduziu, mas muitas empresas ainda mantêm seus empregadores em trabalho em casa e tem repensado a dinâmica e política de trabalho diante do cenário atual e das vantagens e desvantagens identificadas com o home office.

Não se pode esquecer que uma parcela da população continuou trabalhando, principalmente profissionais da saúde, empresários e funcionários ligados a serviços essenciais (abastecimento, agências bancárias etc.), bem como se deve considerar também parcela da população que perdeu emprego ou sofreu redução salarial, como colocado anteriormente, assim como de empresas que tiveram que suspender ou encerrar suas atividades.

\section{Considerações Finais}

A sociedade vive de forma cíclica em crises que se torna difícil entender qual seria o mundo ideal e estável. É constante uma imersão em problemas que exigem soluções 
imediatas e que foram somados a uma pandemia global devastadora e sem uma vacina ainda implantada. A crise do novo coronavírus desafiou um mundo que acreditava ter resposta para tudo devido às novas tecnologias e ao maior número de canais de informação.

No entanto, como coloca Livopetsky (2007, p. 16) "melhoramos muito, pioramos bastante". Se antes as pessoas sonhavam com um futuro melhor, promissor, agora elas o temem. Isso se dá pela desconfiança nos governos, pelos estereótipos difíceis de serem superados, com preconceitos de gênero, sexualidade, assim como pelas desigualdades, pobreza e miséria presentes em todo o mundo, principalmente em países em desenvolvimento como o Brasil.

A capacidade das pessoas de reinventarem vivências de lazer foi positiva em diversos países do mundo. Isso mostra que a sociedade tem a capacidade de mudar, de ser crítica e criativa e de transformar a ordem social vigente a partir de um processo longo e de boa vontade. É possível ver isso nos concertos na janela, nas lives dos artistas, das ações de gastronomia, nas leituras gratuitas, nos eventos para discutir temas de interesse comum, nas doações para pessoas mais impactadas pela pandemia, nas criadas plataformas de venda online ou nos serviços de delivery de produtos de agricultura familiar, de produtores locais e de artesanato que puderam contribuir com enfrentamento e mitigação da crise da Covid-19.

Ainda há muito a ser feito, principalmente para inserir maior parcela da população nas vivências de lazer, não somente as classes sociais mais privilegiadas, e isso necessita de uma ação conjunta entre governos, iniciativa privada e sociedade civil a fim de enfrentar e superar os impactos que a pandemia tem causado em todos os países do mundo. 


\section{REFERENCIAS}

AGRELA, L.; CURY, M. E.; VITORIO, T. Na quarentena, o mundo virou uma live. Revista Exame. 2020. Disponível em: http://exame.com/revista-exame/o-mundo-e-umalive/. Acesso em: 28 jul. 2020.

ARESTA, M; SALINGAROS, N. A importância do espaço doméstico em tempos de COVID-19. Arch Daily. 2020. Disponível em: https://www.archdaily.com.br/br/939395/a-importancia-do-espaco-domestico-emtempos-de-covid-19. Acesso em: 09 ago. 2020.

AVELLAR. Por trás da estratégia da maior live do mundo: Marília Mendonça. Disponível em http://news.bizmeet.com.br/wp-content/uploads/2020/04/Os-bastidoresda-Maior-Live-do-Mundo.pdf. Acesso em: 15 jul. 2020.

BOUÇAS, C. Audiência de TV é a maior em cinco anos. Valor Econômico. 2020. Disponível em: https://valor.globo.com/empresas/noticia/2020/04/03/audiencia-de-tv-ea-maior-em-cinco-anos.ghtml. Acesso em: 28 jul. 2020

BRASIL, Ministério da Saúde. 2020. Covid-19: Painel Coronavírus no Brasil. Disponível em: https://covid.saude.gov.br/ Acesso em: 20 abr. 2020.

CAPITANI, L. 15 museus ao redor do mundo sem sair de casa. Guia da Semana. 2020. Disponível em: https://www.guiadasemana.com.br/turismo/galeria/museus-paraconhecer-

online\#: :text=Museu\%20do\%20Vaticano\%2C\%20Tate\%2C\%20Louvre,e\%20Metrop olitan\%20est\%C3\%A3o\%20na\%20lista.\&text=Sabia\%20que\%20voc\%C3\%AA\%20po de\%20viajar,Metropolitan\%20e\%20at\%C3\%A9\%20o\%20MASP!. Acesso em: 15 jul. 2020.

CATRACA LIVRE. Faça um tour virtual pelos museus mais icônicos dos EUA. Catraca Virtual. 2020. Disponível em: https://catracalivre.com.br/viagem-livre/faca-um-tourvirtual-pelos-museus-mais-iconicos-dos-eua/. Acesso em: 25 jun. 2020.

DECLOEDT, C. Caixa já pagou 179 milhões em auxílio emergencial, diz Pedro Guimarães. UOL Notícias. Disponível https://economia.uol.com.br/noticias/estadaoconteudo/2020/08/27/caixa-ja-pagou-r-179-bi-em-auxilio-emergencial-diz-

guimaraes.htm\#: :text=A\%20Caixa\%20Econ\%C3\%B4mica\%20Federal\%20j\%C3\%A1 ,presidente $\% 20 \mathrm{do} \% 20 \mathrm{banco} \% 2 \mathrm{C} \% 20 \mathrm{Pedro} \% 20 \mathrm{Guimar} \% \mathrm{C} 3 \% \mathrm{~A} 3 \mathrm{es}$. Acesso em: 28 ago. 2020.

O ESTADO DE SÃO PAULO. Spotify tem aumento de assinantes além do esperado durante a pandemia. Caderno Link. 2020. Disponível em: https://link.estadao.com.br/noticias/empresas,spotify-tem-aumento-de-assinantes-alemdo-esperado-durante-a-pandemia,70003287092. Acesso em: 27 jul. 2020.

DECODE, BTG Pactual. O Legado da Quarentena para o Consumo. Mai. 2020. Disponível em: https://lp.decode.buzz/legado-da-quarentena-consumo. Acesso em: 20 jun 2020.

FGV (Fundação Getúlio Vargas) - FGV Projetos. Relatório sobre os impactos econômicos da COVID-19 - Economia Criativa. 2020. Disponível em

licere, Belo Horizonte, v.23, n.3, set/2020. 
https://fgvprojetos.fgv.br/artigos/impactos-economicos-da-covid-19-economia-criativajulho-2020. Acesso em: 09 ago. 2020.

FOIS-BRAGA, H.; BRUSADIN, L. B. Entre as solidões da casa e do mundo: recolhimentos e acolhimentos domésticos de si e dos outros em época de Covid19. Cenário: Revista Interdisciplinar em Turismo e Território, v. 8, n. 14, p. 44 - 54, 29 jun. 2020.

FURCERI, D. F.; LOUNGANI, P.; OSTRY, J. D. Como as pandemias deixam os pobres mais pobres. Fundo Monetário Internacional (FMI), 2020. Disponível em: https://www.imf.org/pt/News/Articles/2020/05/11/blog051120-how-pandemics-leavethe-poor-even-farther-behind\#author1. Acesso em: 28 ago. 2020.

G1. De quarentena por novo coronavírus moradores de cidades da Itália cantam nas janelas. Globo.com. Mundo. 2020. Disponível em: https://g1.globo.com/mundo/noticia/2020/03/13/de-quarentena-por-novo-coronavirusmoradores-de-cidades-da-italia-cantam-nas-janelas-veja-video.ghtml. Acesso em: 20 jul. 2020.

GODOY, D. Netflix ganha 16 milhões de assinantes. no primeiro trimestre com covid19. Revista Exame. 2020. Disponível em: https://exame.com/negocios/netflix-ganha-16milhoes-de-assinantes-no-primeiro-trimestre-com-covid-19/. Acesso em: 20 jul. 2020.

HARARI, Y. N. Na batalha contra o coronavírus, faltam líderes a humanidade. Ebook: Breve Companhia, 2020. Disponível em: https://www.amazon.com.br/batalhacoronav\%C3\%ADrus-1\%C3\%ADderes-humanidade-Companhia-

ebook/dp/B086H52P1N. Acesso em: 05 ago. 2020.

IBGE (INSTITUTO BRASILEIRO DE GEOGRAFIA E ESTATÍSTICA. Pesquisa Nacional por Amostra de Domicílios Contínua - PNAD Contínua 2018: acesso a Internet e a Televisão e posse de telefone móvel celular para uso pessoal - análise dos resultados, $2018 . \quad$ Disponível em https://www.ibge.gov.br/estatisticas/sociais/populacao/9171-pesquisa-nacional-poramostra-de-domicilios-continua-mensal.html?edicao $=26737 \& \mathrm{t}=$ downloads. Acesso em: 08 ago. 2020.

Disponível

Pesquisa Nacional por Amostra de Domicílios - PNAD Covid-19 - julho 2020a. https://agenciadenoticias ibge.gov.br/media/com mediaibge/arquivos/d9eac $24 c 56 c d 44$ 40d7689600048ccd8.pdf. Acesso em: 28 ago. 2020.

Pesquisa Nacional por Amostra de Domicílios - PNAD Covid-19 - Indicadores de Trabalho, 2020b. Disponível em: https://covid19.ibge.gov.br/pnad-covid/. Acesso em: 28 ago. 2020.

JOHN HOPKINS UNIVERSITY (JHU CCA). COVID-19 Dashboard. 2020. Disponível

em https://www.arcgis.com/apps/opsdashboard/index.html\#/bda7594740fd40299423467b4 e9ecf6. Acesso em: 13 abr. 2020. 
LORRAN, T. Seis em 10 brasileiros estão em home office. Jornal Metrópole. 2020. Disponível em: https://www.metropoles.com/brasil/economia-br/seis-em-10-brasileirosestao-em-home-office-registra-pesquisa. Acesso em: 09 ago. 2020,

LIPOVETSKY, G. A sociedade da decepção. Barueri: Manole, 2007.

MARCELLINO, N. C. Estudos do Lazer: uma introdução. 4. ed., Campinas: Autores Associados, 2006.

Política de Lazer: mercadores ou educadores? Os cínicos bobos da corte IN: MARCELlinO, N. C. (Org.). Políticas Públicas de Lazer. Campinas: Editora Alínea, 2008, p. 21-42.

MELO, A. Brasileiro compra mais eletrodomésticos na quarentena. Valor Investe. Disponível em: https://valorinveste.globo.com/objetivo/gastarbem/noticia/2020/04/17/em-casa-brasileiro-compra-mais-eletrodomesticos.ghtml.

Acesso em: 15 jul. 2020.

MERCADO E CONSUMO. Brinquedos e jogos registram alta no e-commerce durante a pandemia. 2020. Disponível em: https://www.mercadoeconsumo.com.br/2020/05/06/brinquedos-e-jogos-registram-altano-e-commerce-durante-a-pandemia/. Acesso em: 25 jun. 2020.

MOTOMURA, O. Reflexões OM (2) sobre como estamos vivendo hoje. Disponível em: https://amana-key.com.br/webinar-aberto-amana-key-mar-20/. Acesso em: 30 mar. 2020.

RENNE, M. 30 museus virtuais para você visitar sem sair de casa. Melhores Destinos. 2020. Disponível em: https://www.melhoresdestinos.com.br/museus-virtuais.html. Acesso em: 27 jul. 2020.

RIBEIRO, C. Pandemia de Covid-19 aumenta interesse dos brasileiros em jardinagem e horta urbana. Revista Globo Rural. 2020. Disponível em: https://revistagloborural.globo.com/Colunas/Cassiano-

Ribeiro/noticia/2020/06/pandemia-de-covid-19-aumenta-interesse-dos-brasileiros-emjardinagem-e-horta-urbana.html. Acesso em: 28 jul. 2020.

RIBEIRO, F. Globoplay tem 2,5 vezes mais assinantes durante a pandemia do que em 2019. Canal Tech. 2020. Disponível em: https://canaltech.com.br/entretenimento/globoplay-tem-25-vezes-mais-assinantesdurante-a-pandemia-do-que-em-2019-166725/. Acesso em: 27 jul. 2020.

SANTOS, B. de S. A cruel pedagogia do vírus. Coimbra: Almedina, 2020.

SÃO PAULO, Governo do Estado - Secretaria de Turismo. Boletim de impactos do COVID-19 no Turismo, 2020a. Disponível em https://www.turismo.sp.gov.br/publico/include/download.php?file=433. Acesso em: 09 ago. 2020.

SEADE. São Paulo contra o novo coronavírus. Boletim Completo. 2020 b. Disponível em: https://www.seade.gov.br/coronavirus/. Acesso em: 20 jul. 2020. 
Governo do Estado, Secretaria de Turismo. Mutirão do Turismo. 2020c. Disponível em: https://mutiraodoturismo.com.br/. Acesso em: 09 ago. 2020.

Governo do Estado. Plano São Paulo. 2020d. Disponível em: https://www.saopaulo.sp.gov.br/planosp/. Acesso em: 27 jul. 2020.

SCHELLER, F. Consumo de vinhos sobe $72 \%$ no $2^{\circ}$. Trimestre e atinge máxima histórica na quarentena. O Estado de São Paulo. Caderno Economia \& Negócios. 2020. Disponível em: https://economia.estadao.com.br/blogs/fernando-scheller/consumo-devinhos-sobe-72-no-2o-trimestre-e-atinge-maxima-historica-na-quarentena/. Acesso em: 04 ago. 2020.

SEVERINO, J. A. Metodologia de Trabalho Científico. 23. ed. rev. atual. São Paulo: Cortez, 2007.

TRIVIÑOS, A. N. S. Introdução à pesquisa em ciências sociais: a pesquisa qualitativa em educação. São Paulo: Atlas, 2013.

\section{Endereço dos/as Autores/as:}

Ana Cristina Fernandes Clemente

Universidade de São Paulo - EACH

Rua Arlindo Bettio, 1000 - Ermelino Matarazzo

São Paulo - SP - 03.828-000

Endereço Eletrônico: ana.clemente@usp.br

Edmur Antonio Stoppa

Universidade de São Paulo - EACH

Rua Arlindo Bettio, 1000 - Ermelino Matarazzo

São Paulo - SP - 03.828-000

Endereço Eletrônico: stoppa@usp.br 